in Krystallen auszuscheiden, die man sodann zur nächsten Bereitung aufheben kann. Der lełzte Rest der sauren Mutterlauge kann endlich weggeschüttet werden.

\title{
Chemische Untersuchung der Beeren von Vitis sylvestris (wilde Rebe); \\ von
}

Dr. C. Riegel in Carlsruhe.

Diese in der Umgegend von Carlsruhe dies - und jenseits des Rheins hie und da vorkommende Pflanze, von der der Verfasser der Flora badensis sagt: "est sine dubio Labrusca veterum, de qua pulcherrime el vere Virgilius, in Bucol.

Aspice ut antrum

Sylvestris raris sparsit Labrusca racemis. ist eine Ranken - oder Schlingpflanze, die bisweilen baumartig wird und die höchsten Bäume und Sträucher überklettert. Sie hat herzförmige, fast 3lappige, gezähnte, unten behaarte Blätter. Sic unterscheidet sich von der sehr ähnlichen Vitis vinifera durch die schmälern, spitzern und tiefer gezähnten Lappen der Blätter, kleinere Blüthentrauben, die gelblich oder graulichweiss und meist diöcisch sind. Die Beeren sind fast rund, einfächerig, mit $3-5$ steinharten, glatten Samen, im reifen Zustande roth oder violettroth, fleischig, saftig, mit einem dunkelrothen Fleische von eigenthümlichem, süsslichem, nicht unangenehmem Geschmack; von Vögeln werden sie sehr gern gefressen. Viele der Beeren gelangen nicht zur Reife und sind noch im November und December sehr hart, grün, sauer und sehr herb.

Der süsse, aber eigenthümliche Geschmack der reifen Beeren und die Verwandtschaft der Pflanze mit der Vitis vinifera gab Veranlassung zur Erforschung der Bestandtheile der Beeren, um zu ermitteln, in wiefern diese mit denen der Weintrauben ubereinstimmen. 
I. Die im Monat November v. J. gesammelten Reifen wurden zerquetscht und ausgepresst, der Rückstand wiederholt. mit kaltem Wasser behandelt und ausgepresst, sämmtliche Flüssigkeiten vereinigt und bis zur vollständigen Fällung mit einer Auflösung von neutralem essig; saurem Bleioxyd versetzt. Den entstandenen grünen Niederschlag in Wasser zertheilt, zersetzte man durch Schwefelwasserstoffgas und filtrirte das entstandene Schwefelblei ab; bei der Digestion mil Alkohol trat es Spuren eines fettig-harzigen Körpers und Farbstoff an denselben ab. Die vom Schwefelblei abfiltrirte saure Flüssigkeit wurde mit Aetzbaryt versetzt und der dadurch entstandene Niederschlag näher untersucht; er bestand aus weinsteinsaurem, äpfelsaurem und einẹ geringen Menge citronensauren Baryts. Die von diesen Salzen abfiltrirte Flüssigkeit wurde zur Trockne verdunstet und mit Aether digerirt, der nun Spuren von Chloropbyll daraus aufnahm, Alkohol entzog ihm eine geringe Menge Farbstoff, auf den wir weiter zurückkommen werden. Der in Aether und Alkohol unlösliche Theil der Salzmasse bestand aus weinsaurem, äpfelsaurem und citronensaurem Baryt.

II. Die vom Bleizucker-Niederschlag abfiltrirte Flüssigkeit gab mit basisch essigsaurem Bleioxyd (Bleiessig) einen blaugrün gefärbten Niederschlag, der nach gehörigem Auswaschen mit Schwefelwasserstoff zersetzt wurde; die vom Schwefelblei abfiltrirte Flüssigkeit ward möglichst schnell im Wasserbade abgedampfl, der Rückstand in einem verschlossenen Gefässe so oft mit Alkohol von 0,85 spec. Gew. digerirt, als dieser sich noch färbte. Die alkoholischen Ausziige wurden durch Destillation von dem grössten Theile des Alkohols befreil und der Ruickstand durch Abdampfen im Wasserbade möglichst schnell zur Trockne gebracht. Dieser Ruickstand besteht aus dem reinen rothen Farbstoff der Beeren, der in Alkohol und Wasser löslich, in Aether unlöslich ist; die wässerige Lösung hinterlässt beim Verdunsten im Wasserbade einen Rückstand, der nicht mehr ganz in Wasser und noch 
weniger in Alkohol löslich, dagegen sehr leicht löslich in den Auflösungen der Alkalien ist, eine Art extractartigen Absatzes und ein Oxydationsproduct des reinen Farbstoffs zu sein scheint. Die wässerige Lösung: des letztern giebt mit ein wenig Kalkmilch versetzt einen graugrünen Niederschlag, Die von diesem abfiltrirte Fliissigkeit ist roth gefärbt und giebt. mit einem Ueberschuss von basischessigsaurem Bleioxyd eine bläulich-grüne Fällung, aus welcher nach der oben angegebenen Weise der Farbstoff unverändert erhalten werden kann. Der Farbstoff erhält sich in seiner alkoholischen Auflösung lange Zeit unzersetzt, ebenso in der wässerigen Lösung mit Zusatz von geringer Menge organischer Säuren, wie Citronen -, Weinsteinsäure u. s. w. Diese, mehr aber noch die Mineralsäuren, verändern den Farbstoff ins Hochrothe, Alkalien dagegen ins Blaue, durch überschüssiges Alkali geht die blaue Farbe ins Grüne. Kalk -, Bleioxyd und die meisten uibrigen Metalloxydsalze geben mit der wässerigen Lösung grün- oder bläulich - gruin gefärbte Niederschläge, die bisweilen einen Stich ins Bräunliche zeigen.

Der Farbstoff kann auch gewonmen werden, wenn man den frisch ausgepressten Saft der Beeren mit fein geriebener Kreide und darauf mil etwas frischem Aetzkalk vermischt. Die entstandene Fallung von der überstehenden Flüssigkeit abfiltrirl, letzlere mit ein wenig essigsaurem Bleioxyd vermischt und den anfänglich entstandenen blaugrünen Niederschlag entfernt. Dann wird vollständig durch essigsaures Bleioxyd gefällt, der grüne Niederschlag gehörig ausgewaschen und noch im feuchten Zustande durch Schwefelwasserstoffgas zersetzt, das Schwefelblei abfiltrirt und der durch schnelles Verdampfen des Filtrats zur Trockne erhaltene Rïckstand mit wasserfreiem Alkohol behandelt, von der Lösung der Alkohol durch Destillation entfernt und der Rückstand zur Trockne gebracht.

Der oben bei der Bebandlung mil Alkohod von 0,85 spec. Gew. verbliebene Riuckstand löste sich kaum sichtlich in Wasser, mehr darin aufquellend; aus diesem 
Grunde behandelte man denselben mit einer verdünnten Lösung von Kalihydrat in gelinder Wärme, wodurch beinahe vollständige Auflösung erzielt ward. Diese liess auf Zusatz von Säuren, eine gefärbte Gallerte fallen, welche Pectinsäure ist; es enthielt demnach der Saft der Beeren Pflanzengallerte oder Pectin.

III. Die vom Bleiessig- Niederschlag abfiltrirte Flüssigkeit wurde durch Schwefelwasserstoffgas von ihrem Gehalt an Bleioxyd befreit, der Ueberschuss des ersteren durch Verdampfen entfernt; in der rückständigen Flüssigkeit liess sich durch die bekannten Reagentien die Gegenwart von einer geringen Menge von Kalk und Kali, sowie einer grösseren Menge von Traubenzucker nachweisen.

IV. Durch Behandlung des Pressriickstandes der frischen reifen Beeren mit Alkohol von 0,85 spec. Gew., erhielt man eine ziemlich dunkel-braunrothe Fluissigkeit, wovon der Alkohol durch Destillation entfernt ward; den Hückstand, nachdem er im Wasserbade zur Trockne verdampft worden, behandelte man mit Aether, welcher daraus eine geringe Menge Chlorophyll aufnahm. Der im Aether unlösliche Theil enthielt nebst etwas Zucker und Spuren von Harz, eine ziemliehe Menge des oben beschriebenen Farbstoffs.

Die Untersuchung hat demnach ergeben, dass die Beeren der wilden Rebe enthalten: Chlorophyll, Harz, rothen Farbstoff, Pectin oder Pflanzengallerte, Gummi, Traubenzucker, Aepfelsäure, Weinsäure, Citronensäure, Kalk und Kali. Der geringe Gehalt an Basen, wovon nur Kali und Kalk aufgefunden werden konnten, giebt den Beleg dafür, dass die genannten Säuren zum grössten Theile im freien Zustande in den Beeren enthalten sind, welchem Umstande der Saft seine rothe Farbe verdankt. Vergleichen wir mit dieser Zusammensetzung die Bestandtheile des sauren Saftes der unreifen, so wie des Saftes der reifen Trauben, so finden wir in Bezug auf die wichtigern Bestandtheile eine ziemliche Uebereinstimmung (mit Ausnahme des Farbstoffs), die sich bei einer quanlitativen Bestimmung derselben vielleicht noch deutlicher zei- 
gen dürfte. Die Aehnlichkeit der reifen Beeren der Vitis sylvestris mit den reifen Beeren von-Sambucus Ebulus, nigra und Vaccinium Myrtillus veranlasste noch einige vergleichende Versuche. Die Beeren von Sambucus Ebulus und die von Sambucus nigra (bekannt unter dem Namen Grana Actes), enthatten einen rothen Farbstoff, der auf die oben angegebene Weise isolirt werden kann, in Wasser und Alkohol löslich ist, durch Säuren hochroth, durch Alkalien violett gefärbt, durch Bleiessig und andere Metallsalze bläulich-grün gefällt wird, im Wesentlichen also mit dem beschriebenen rothen Farbstoff der Beeren der wilden Rebe uibereinstimmt. Die ubrigen Bestandtheile der Beeren von Sambucus Ebulus und nigra sind geringe Mlengen von Chlorophyll und Harz, bauptsächlich Aepfelsäure mit Spuren von Citronensäure, Z Zucker und Pectin. Weinsteinsäure konnte nicht darin aufgefunden werden.

Die Heidelbeeren enthalten einen ähnlichen Farbstoff, der durch die verschiedenen genannten Reagentien dieselben Färbungen und Fällungen erleidet; der Saft enthält eben eine geringe Menge eisengrünenden Gerbstoffs, Zucker, Aepfel - und Citronensäure und gleichfalls Pectin. Auch hier konnte keine Weinsteinsäure aufgefunden werden.

Obgleich die Beeren der wilden Reben hinsichtlich ihrer Bestandtheile sich sehr den oben genannten Frichten aus der Familie der Sambucineen und Vaccinieen nähern, so unterscheiden sie sich wesentlich davon durch ihren Gehalt an Weinsäure, welche bekanntlich reichlich in der Familie der Ampelideen vorkommt.

Nachdem die vorstehende Lntersuchung im Laufe des vorigen Winters, soweit sie die Beeren der Vitis sylvestris betrifft, beendet war, wurden erst im Laufe dieses Herbstes die Versuche mit den Beeren von Sambucus Ebulus und nigra und von. Vaccinium Myrtillus angestellt. Kürzlich (October 1847) sammelte ich von demselben Stamme eine ziemliche Menge von Beeren der Vitis sylvestris und die diesjährige Untersuchung ergab einen grösseren Gebalt 
an Pectin und namentlich an Weinsäure. Diese Beobachtung veranlasst mich, meine Versuche mit den tibrigen genannten Beeren im Laufe des kommenden Jahres wieder aufzunehmen, wodurch sich Gelegenheil darbieten wird. sich zu überzeugen, in wie weit eine Bestätigung zur Berechtigung oben ausgesprochenen Schlusses darin zu suchen oder zu finden ist.

\section{Ueber Gummi arabicum saturninum seu plumbicum;}

von

Dr. Riegel,

A potheker. in Carlsruhe.

Von cinem Arzte, der das Blcigummi häufg anwendet und ausgezeichnete Erfolge davon beobachtete, bin ich um Ermittelung der Zusammensetzung dieses Präparats angegangen worden. Als ich in den verschiedenen chemischen Werken über diese Zusammensetzung nachschlug, fand ich verschiedene Angaben. So führt Berzelius in seinem Lebrbuche der Chemie an, dass die Verbindung des Bleioxyds mit Gummi aus 61,75 Gummi und 38,25 Bleioxyd oder 1 Atom von jedem bestehe, während $L \ddot{~ o ̈-~}$ wig in seiner Chemie der organischen Verbindungen erwähnt, dass das Gummibleioxyd nach Peligot aus $2 \mathrm{At}$. Bleioxyd und 1 At. Gummi, $2 \mathrm{PbO}+\mathrm{C}^{1}{ }^{2} \mathrm{H}^{\circ} \mathrm{O}^{9}$, bei $180^{\circ}$ getrocknet bestehen soll. Diese Formel ergiebt für $100 \mathrm{Th}$ 24,62 Bleioxyd und 70,38 Gummi. Diesc verschiedenen Angaben konnten mich nicht befriedigen, und ich sah mich genöthigt, durch cigene Versuche den Bleigehalt zu bestimmen. Bekanntlich gicbt die Auflösung des arabischen Gummis, Arabins mit ncutralem essigsaurem Bleioxyd, keinen Niederschlag, indem der anfangs entstehende sich in der freiwerdenden Essigsäure auflöst. Man erhält die Verbindung durch Vermischen einer Gummiaullösung mit 